\title{
Modelling distribution patterns and habitat preference of the invasive green alga Caulerpa racemosa in the Saronikos Gulf (Eastern Mediterranean)
}

\author{
Stelios Katsanevakis ${ }^{1, *}$, Maria Salomidi ${ }^{2}$, Aliki Panou ${ }^{3}$ \\ ${ }^{1}$ Institute of Marine Biological Resources, and ${ }^{2}$ Institute of Oceanography, Hellenic Centre for Marine Research, \\ $46.7 \mathrm{~km}$ Athens-Sounio Avenue, 19013 Anavyssos, Greece \\ ${ }^{3}$ Archipelagos - Environment and Development NGO, 28100 Lourthata, Kefalonia, Greece
}

\begin{abstract}
Although the invasive alga Caulerpa racemosa has exhibited an excessive rate of proliferation and has invaded the entire Mediterranean Sea basin within the last $18 \mathrm{yr}$, its spatial distribution patterns remain largely unknown. A 2-component modelling approach based on generalized additive models was applied to model the density of $C$. racemosa fronds in relation to spatial and environmental variables. A bimodal distribution of presence probability in relation to depth was observed, with higher probabilities of occurrence at very shallow bottoms $(<4 \mathrm{~m})$ and at depths between $\sim 15$ and $30 \mathrm{~m}$. Presence probability steadily decreased at greater depths. Frond density was markedly higher in rocky habitats than in Posidonia oceanica beds or on sandy/muddy bottoms. The highest frond densities were observed in the southeastern part of the Saronikos Gulf, which is considered to be the area of initial establishment of the species in the Gulf; this indicates that time favours the steady expansion and further dominance of this species.
\end{abstract}

KEY WORDS: Caulerpa racemosa · Generalized additive models · Greece $\cdot$ Invasive macrophytes · Spatial distribution patterns

\section{INTRODUCTION}

Biological invasions in marine habitats represent a recognized worldwide threat that has a strong impact on biodiversity and local economies (Pimentel et al. 2005, Streftaris \& Zenetos 2006). The Mediterranean Sea is one of the regions most severely affected by alien marine invasions. According to a recent update, 947 alien species had been reported in the Mediterranean Sea by December 2009, raising the rate of introductions to 1 species every 1.5 wk (Zenetos 2010). Of these introductions, $>100$ exotic macrophytes have reportedly been established in the Mediterranean Sea (Zenetos et al. 2008).

The green alga Caulerpa racemosa (Forsskål) J. Agardh sensu lato (Chlorophyta: Bryopsidales) is widely distributed in tropical and warm temperate seas (Verlaque et al. 2003). In the Mediterranean, the species is encountered in 3 distinct varieties: (1) Caulerpa racemosa var. turbinata (J. Agardh) Eubank / uvifera (C. Agardh) J. Agardh, which has been observed in the Levantine Sea and Tunisian coasts, (2) C. racemosa var. lamourouxii f. requienii (Montagne) Weber-van Bosse, which is mainly observed in the Levantine Sea, and (3) the recently introduced C. racemosa var. cylindracea (Sonder) Verlaque, Huisman, and Boudouresque, which is widely distributed in the entire Mediterranean (Verlaque et al. 2000, 2003, in press). The last variant was first observed in Libya in 1990 (Nizamuddin 1991), but its identity and origin remained puzzling for at least a decade, until ad hoc morphological and genetic studies classified it as C. racemosa var. cylin- 
dracea (Sonder) Verlaque, Huisman, and Boudouresque, of southwestern Australian origin (Verlaque et al. 2003, Klein \& Verlaque 2008).

This new variety (hereafter, Caulerpa racemosa) has rapidly spread throughout the entire Mediterranean basin, reaching as far as the Canary Islands in the eastern Atlantic Ocean (Verlaque et al. 2004). The rate of expansion of C. racemosa appears to be among the most significant rates ever recorded for an invasive species (Streftaris \& Zenetos 2006, Klein \& Verlaque 2008). The species has been reported to occur in at least 14 Mediterranean countries (Albania, Algeria, Croatia, Cyprus, France, Greece, Italy, Libya, Malta, Monaco, Montenegro, Spain, Tunisia, and Turkey) and all major Mediterranean islands. It grows on all kinds of substrata, including both polluted and unpolluted areas between 0 and $70 \mathrm{~m}$ depth, and shows an excessive rate of proliferation (Streftaris \& Zenetos 2006, Macic \& Kascelan 2007, Klein \& Verlaque 2008, Tsiamis et al. 2008, P. Francour pers. comm.).

Caulerpa racemosa has stolons that can quickly elongate, and easily overgrow other macroalgal (Piazzi et al. 1997) or invertebrate species (Kružić et al. 2008, Baldacconi \& Corriero 2009). It has a high potential for dispersal by fragmentation and re-establishment of stolons (Ceccherelli \& Piazzi 2001), formation of propagules (Renoncourt \& Meinesz 2002), and sexual reproduction (Panayotidis \& Žuljević 2001). This latter characteristic has been suggested to be the most probable explanation for the species' continuous spread in both Mediterranean basins as opposed to its congeneric alien invasive C. taxifolia, which only reproduces vegetatively (Meinesz \& Hesse 1991, Panayotidis 2006).

In Greece, small patches of Caulerpa racemosa were initially reported from 2 oligotrophic eastern Ionian coasts (Zakynthos Island and Pylos Bay) (Panayotidis \& Montesanto 1994). These first occurrences were soon followed by new records from other distant Aegean locations (Panayotidis \& Montesanto 1998). In the Saronikos Gulf, C. racemosa was first observed in 1996, established in an unpolluted bay near the southeastern entrance of the Gulf (Panayotidis \& Montesanto 2001), and has rapidly spread from this location (Panayotidis et al. 2006).

Records of Caulerpa racemosa in the literature are often imprecise. Simple maps indicating the presence of the species have been compiled, and the length of affected coastlines has been roughly estimated in some countries (Piazzi et al. 2005). However, these analyses were performed without a standardized method (Klein \& Verlaque 2008). The patterns of spatial distribution of the species in the Mediterranean Sea and the dependence of algal density on spatial and environmental factors have not been properly assessed so far.
In the present study, generalized additive models (GAMs; Hastie \& Tibshirani 1990) were utilized to model the density of Caulerpa racemosa fronds to increase our knowledge on the distribution patterns of the species. GAM is a nonparametric technique that offers the required flexibility and does not limit the analysis to the concept of a strict parametric shape. GAMs are increasingly used in ecological studies of the spatial distribution and abundance of marine fauna (e.g. Daskalov et al. 2003, Katsanevakis 2007, Maravelias et al. 2007, Herr et al. 2009, Murase et al. 2009, Laidre et al. 2010) because of the ecological interpretability of the nonparametric response curves and the flexibility of GAMs to fit the data closely. To our knowledge, GAMs have not been used to investigate the spatial distribution and density of any marine flora until the present study.

\section{MATERIALS AND METHODS}

Study area. The Saronikos Gulf (see Fig. 1) is an embayment of the south Aegean Sea (E. Mediterranean, Greece) that is surrounded by the Attica peninsula coast in the north and the Peloponnesus peninsula coasts in the west and southwest. The total surface area of the Saronikos Gulf is $\sim 2850 \mathrm{~km}^{2}$ and stretches along a coastline length of $\sim 744 \mathrm{~km}$. The bottom of the eastern part of the Gulf is relatively flat with a mean depth of $90 \mathrm{~m}$. The western part is deeper and has an elongated north-south trough with maximum depths of $\sim 200 \mathrm{~m}$ in the north and $\sim 450 \mathrm{~m}$ in the south (Kontoyiannis et al. 2005). Tidal effects are negligible, while seasonal flows are basically induced by thermohaline effects and strongly modified by winds (H. Kontoyiannis pers. comm.). A $48 \mathrm{~km}$ wide opening connects the Saronikos Gulf with the Aegean Sea, thus allowing a fast renewal of its water masses (5-10 d for the eastern part of the Gulf; Zeri et al. 2009).

The Saronikos Gulf receives treated sewage effluents from the Athens metropolitan area through a deep underwater outlet situated near Psitallia islet on the northeast of the Gulf. These effluents, as well as pollution from the industrialized areas in the northern and northwestern coasts and the port of Piraeus, are known to account for a distinct ecological quality gradient, which ranges from poor near the outfall, moderate in the western region, and high in the eastern and southern subregions (Orfanidis et al. 2001, Simboura et al. 2005). The Saronikos Gulf is considered as a hotspot of alien macrophytes, partly because of intense shipping (Piraeus is one of the most important ports globally) and the role of the South Aegean Sea as a migration route for Red Sea species entering through the Suez Canal (Lessepsian migrants) and further expanding westwards (Tsiamis et al. 2010). 
Fieldwork. Twenty line transects extending from the shore perpendicular to the depth contours were defined in the study area. Unbiased design-based inference requires that the line transects in the study area be randomly placed, or be on a grid of systematically spaced lines that are randomly superimposed on the study area. However, with a model-based approach such as the one used in this study, the line transects are not required to be located according to a formal and restrictive survey sampling scheme, although a good spatial coverage of the study area is desirable. Thus, a sampling scheme that provided good spatial coverage as well as sufficient samples in all primary habitat types was applied. Sampling effort was increased (i.e. more closely placed transects) in areas of high Caulerpa racemosa abundance to increase the sample size of nonzero counts. The transect lengths were $200 \mathrm{~m}$, unless a maximum depth of $\sim 40 \mathrm{~m}$ before obtaining this length was reached.

A more or less pronounced winter regression has been observed in the cover, biomass, and frond density of Caulerpa racemosa in various Mediterranean regions (Klein \& Verlaque 2008 and references therein). Due to this seasonal variation in C. racemosa frond density, the period of peak density (summer-autumn) was chosen as the most appropriate time for conducting this survey. Thus, all field measurements were performed between 1 August and 15 November 2008.

Each line transect was defined with a nylon line that was deployed using a diving reel while SCUBA diving. The line was marked with water-resistant numbered signs every $5 \mathrm{~m}$. After deploying the line, the number of algal fronds (erect axes) within a $20 \times 20 \mathrm{~cm}$ stainless steel quadrat was counted at each sign. For each quadrat, the habitat type and depth (measured by a dive computer) were logged on an underwater plastic slate. Although sampling was principally nondestructive, careful removal of various filamentous epiphytes (mainly Ectocarpales and Cladophorales) was at times necessary to maintain visual access to the understory.

Modelling of frond counts. Inference was based on the information theory approach (Burnham \& Anderson 2002). According to this approach, data analysis is taken to mean the integrated process of a priori specification of a set of candidate models (based on the science of the problem), model selection based on the principle of parsimony according to Akaike's information criterion (AIC; Akaike 1973), and the estimation of parameters and their precision. Model selection based on information theory is a relatively new paradigm in biological sciences and has been recommended as an improved and more robust alternative than traditional approaches of hypotheses testing (Akaike 1981, Burnham \& Anderson 2002).
A distinctive feature of data collected on the abundance of organisms is the tendency to contain many 0 values. When the number of $0 \mathrm{~s}$ is large such that the data are not readily fitted to standard distributions (e.g. the Poisson distribution), the data set is referred to as 'zero-inflated' (Welsh et al. 1996, Barry \& Welsh 2002, Martin et al. 2005). Failure to account for zeroinflation will cause bias in parameter estimations and the associated measures of uncertainty, can reduce the capability to detect relationships, or lead to incorrect inference in the worst scenario (Martin et al. 2005). Several methods have been proposed to deal with zeroinflated datasets (Welsh et al. 1996, Martin et al. 2005). One such approach is to use 2-component models (also known as conditional or hurdle models). In the 2-component modelling approach, the response is modelled as having 2 states: a state in which no 'objects' (fronds in this case) occur and a state in which objects occur with varying levels of abundance. Using this approach, the probability that a species is present is first estimated, and, given that it is present, the relative mean number of individuals observed is then modelled.

GAMs (Hastie \& Tibshirani 1990) have the general formulation

$$
f\left(y_{i}\right)=L P_{i}=c+\Sigma_{m} S_{m}\left(z_{m i}\right)+\Sigma_{r} F_{r i}
$$

where $y$ is the response variable, $f$ is the link function, $L P$ is the linear predictor, $C$ is the intercept, $s_{m}(\cdot)$ is the 1-dimensional smooth function for predictor variable $m, z_{m i}$ is the value of covariate $m$ for plot $i$, and $F_{r}$ are categorical predictors.

To model the probability, p, of Caulerpa racemosa presence, a binomial error distribution was assumed and a logit link (canonical link for the binomial family) was used, where $f(p)=\log (\mathrm{p} / 1-\mathrm{p})$, i.e. the natural logarithm of the odds of presence (Welsh et al. 1996, Barry $\&$ Welsh 2002). Thus, the general GAM becomes

$$
\operatorname{logit}(\hat{\mathrm{p}})=\log (\hat{\mathrm{p}} / 1-\hat{\mathrm{p}})=C+\sum_{m} S_{m}\left(Z_{m i}\right)+\sum_{r} F_{r i}
$$

Four predictor variables were used: (1) depth, (2) habitat type (htype), (3) longitude (lon), and (4) latitude (lat). Habitat type was a categorical predictor variable. Four different habitat types were identified: Posidonia oceanica meadows (PO), Cymodocea nodosa beds (CN), unvegetated sandy/muddy bottoms (S), and rocky bottoms (R). The other 3 covariates were continuous, with depths ranging between 0.3 and $42 \mathrm{~m}$, east longitudes between $23.034^{\circ}$ and $24.010^{\circ}$, and north latitudes between $37.460^{\circ}$ and $37.975^{\circ}$.

Eight different GAMs $\left(h_{i}, i=0\right.$ to 7$)$ were fitted (Table 1). Model $h_{0}$ was the null model, with no predictor variable. The smooth functions $s_{m}(\cdot)$ were represented using regression splines that were estimated by penalized iterative least squares (Wood 2006). The optimum degree of smoothing was defined by mini- 
Table 1. Summary of the parameterisation of the 8 candidate models $h_{i}$ of the probability of Caulerpa racemosa presence. For each model, the Akaike information criteria AICs, Akaike differences $\Delta_{i}$, Akaike weights $w_{i}$, unbiased risk estimator (UBRE) scores, deviance explained, and estimated degrees of freedom (edf) are given. Models with substantial support $\left(\Delta_{i}<2\right)$ are shown in bold. lon: longitude, lat: latitude, htype: habitat type

\begin{tabular}{|c|c|c|c|c|c|c|c|}
\hline & Model & AIC & $\Delta_{i}$ & $w_{i}(\%)$ & $\begin{array}{l}\text { UBRE } \\
\text { score }\end{array}$ & $\begin{array}{c}\text { Deviance } \\
\text { explained (\%) }\end{array}$ & edf \\
\hline$h_{0}$ & Null & 351.9 & 130.7 & 0.0 & 0.003 & 0.0 & 1.0 \\
\hline$h_{1}$ & $s($ lon $)+s($ lat $)$ & 236.1 & 14.8 & 0.0 & -0.681 & 36.2 & 6.4 \\
\hline$h_{2}$ & $s($ depth $)$ & 353.1 & 131.8 & 0.0 & -0.522 & 0.2 & 2.0 \\
\hline$h_{3}$ & htype & 308.1 & 86.9 & 0.0 & -0.039 & 14.2 & 4.0 \\
\hline$h_{4}$ & $s($ lon $)+s($ lat $)+s($ depth $)$ & 221.3 & $\mathbf{0 . 0}$ & 82.8 & -0.701 & 42.8 & 10.5 \\
\hline$h_{5}$ & $s($ lon $)+s($ lat $)+$ htype & 235.0 & 13.8 & 0.1 & -0.682 & 37.9 & 8.9 \\
\hline$h_{6}$ & $s($ depth $)+$ htype & 307.2 & 85.9 & 0.0 & -0.584 & 15.1 & 5.0 \\
\hline$h_{7}$ & $s($ lon $)+s($ lat $)+s($ depth $)+$ htype & 224.4 & 3.2 & 17.1 & -0.696 & 43.5 & 13.4 \\
\hline
\end{tabular}

mizing the unbiased risk estimator (UBRE; Craven \& Wahba 1979). AIC and AIC differences, $\Delta_{i}=\mathrm{AIC}_{i}-$ $\mathrm{AIC}_{\text {min }}$, were computed over all candidate models $h_{i}$. Models with $\Delta_{i}>10$ have essentially no support and were omitted from further consideration, while all models with $\Delta_{i}<2$ have substantial support (Burnham \& Anderson 2002).To quantify the plausibility of each model, given the data and a set of 6 models, the 'Akaike weight' $w_{i}$ of each model was calculated as

$$
w_{i}=\frac{\exp \left(-0.5 \Delta_{i}\right)}{\sum_{j} \exp \left(-0.5 \Delta_{j}\right)}
$$

The Akaike weight is considered as the weight of evidence in favour of model $i$ being the actual best model in the available set of models (Akaike 1983, Buckland et al. 1997, Burnham \& Anderson 2002).

The expected number of Caulerpa racemosa fronds in $20 \times 20 \mathrm{~cm}$ experimental plots, conditional on the species being present, was related to predictor variables using GAMs of the general formulation

$$
f\left(\mathrm{E}\left[\hat{\mathrm{n}}_{i}\right]\right)=L P_{i}=c+\Sigma_{m} S_{m}\left(z_{m i}\right)+\Sigma_{r} F_{r i}
$$

A left truncated negative binomial error distribution was assumed with a log link (canonical link for the negative binomial) (Welsh et al. 1996). The smooth function $s_{m}(\cdot)$ was represented using cubic regression splines. The optimum degree of smoothing was defined based on the AIC, following an optimization procedure described in Stasinopoulos \& Rigby (2007). Three predictor variables were used: (1) time, (2) depth, and (3) htype. C. racemosa was never observed in Cymodocea nodosa beds; thus, htype included only 3 habitat types (PO, R, and $\mathrm{S})$. Time was included as a covariate to account for possible temporal variation in frond density. This was measured in days, with the value 1 corresponding to 1 August 2008, and ranged from 1 to 105 . Eight different GAMs $\left(g_{i}, i=0\right.$ to 7 ) were fitted, where model $g_{0}$ was the null model, with no predictor variable (Table 2). Model selection in the set of candidate models was based on AICs.

For fitting the GAMs, the packages mgcv (Wood 2000, 2006), gamlss, and gamlss.tr (Stasinopoulos \& Rigby 2007) were used in R v. 2.5.1 (R Development Core Team 2007).

\section{RESULTS}

Rocky bottoms were more common at depths $<10 \mathrm{~m}$, Posidonia oceanica meadows were more frequent at depths between 15 and $25 \mathrm{~m}$, and Cymodocea nodosa was the least abundant habitat type, which was mostly confined to shallow waters (Table 3). Caulerpa racemosa was observed in $6.6 \%$ of the sampled quadrats with a maximum observed density of 67 fronds $400 \mathrm{~cm}^{-2}$

Table 2. Summary of the parameterisation of the 8 candidate models $g_{i}$ of the abundance of Caulerpa racemosa fronds in $20 \times 20 \mathrm{~cm}$ plots, conditional on presence. For each model, the Akaike information criteria AICs, Akaike differences $\Delta_{i}$, Akaike weights $w_{i}$, deviance explained, and estimated degrees of freedom (edf) are given. Models with substantial support $\left(\Delta_{i}<2\right)$ are given in bold. htype:

\begin{tabular}{|c|c|c|c|c|c|c|}
\hline & Model & AIC & $\Delta_{i}$ & $w_{i}(\%)$ & $\begin{array}{c}\text { Deviance } \\
\text { explained (\%) }\end{array}$ & edf \\
\hline$g_{0}$ & Null & 322.9 & 19.5 & 0.0 & 0.0 & 2.0 \\
\hline$g_{1}$ & $s($ time $)$ & 307.2 & 3.8 & 8.5 & 6.8 & 5.0 \\
\hline$g_{2}$ & $s($ depth $)$ & 323.9 & 20.5 & 0.0 & 0.3 & 3.0 \\
\hline$g_{3}$ & htype & 314.3 & 10.9 & 0.2 & 4.0 & 4.0 \\
\hline$g_{4}$ & $s($ time $)+s($ depth $)$ & 310.6 & 7.2 & 1.6 & 7.9 & 8.5 \\
\hline$g_{5}$ & s(time) + htype & 303.4 & 0.0 & 57.5 & 9.2 & 7.0 \\
\hline$g_{6}$ & $s($ depth $)+$ htype & 313.8 & 10.4 & 0.3 & 6.9 & 8.4 \\
\hline$g_{7}$ & $s($ time $)+s($ depth $)+$ htype & 304.6 & 1.2 & 31.8 & 9.9 & 8.7 \\
\hline
\end{tabular}
habitat type 
Table 3. Relative distribution of habitat types in different depth strata in the study area, based on the recorded data for the sampled quadrats. PO: Posidonia oceanica meadows; $\mathrm{CN}$ : Cymodocea nodosa beds; R: rocky bottoms; S: unvegetated sandy/muddy bottoms

\begin{tabular}{|lccccc|}
\hline $\begin{array}{l}\text { Depth } \\
\text { strata }(\mathrm{m})\end{array}$ & \multicolumn{4}{c}{ \% of sample in each habitat type } & Sample \\
& PO & CN & R & S & size \\
\hline $0-5$ & 16.2 & 9.7 & 37.4 & 36.7 & 278 \\
$5-10$ & 27.7 & 2.4 & 28.3 & 41.6 & 166 \\
$10-15$ & 27.5 & 3.8 & 8.8 & 60.0 & 80 \\
$15-20$ & 35.6 & 2.3 & 5.7 & 56.3 & 87 \\
$20-25$ & 37.7 & 1.6 & 6.6 & 54.1 & 61 \\
$25-30$ & 5.7 & 0.0 & 8.6 & 85.7 & 35 \\
$>30$ & 0.0 & 0.0 & 3.1 & 96.9 & 32 \\
\hline
\end{tabular}

(Table 4). The species was absent from the western and northern Saronikos Gulf; the highest frond densities were observed in the southeastern part of the gulf (Fig. 1).

The best model of the probability, p, of Caulerpa racemosa presence was $h_{4}$ (Table 1 ), which included univariate smooth functions of lon, lat, and depth. All other models had essentially no support $\left(\Delta_{i}>10\right)$, except for model $h_{7}$, which had some support $\left(\Delta_{7}=3.2\right.$, $w_{7}=17.1 \%$ ). Model $h_{4}$ was nested within $h_{7}$, with $h_{7}$ having htype as an extra predictor variable. However, model $h_{7}$ was not further considered, and $h_{4}$ was selected as the single model for inference, since $\Delta_{7}>2$ and htype was not significant $\left(\chi^{2}, \mathrm{p}=0.46\right)$.

The expression of $h_{4}$ was $\operatorname{logit}(\hat{p})=$

$$
-5.11+s_{1}\left(\text { lon, 4.87) }+s_{2}(\text { lat }, 1.00)+s_{3}(\text { depth, 3.60) }\right.
$$

where the smooth functions of predictors $s_{m}\left(z_{m}\right.$, edf) (edf being the estimated df) are given in Fig. 2. To get actual probabilities of presence for specific values of lon, lat and depth, the corresponding values of the smooth terms (from Fig. 2) were entered in the above expression of $\operatorname{logit}(\hat{p})$. There was a bimodal distribution of presence probability in relation to depth, with higher probabilities at very shallow bottoms $(<4 \mathrm{~m})$ and at depths between $\sim 15$ and $30 \mathrm{~m}$. The highest probabilities of presence were observed at the highest longitudes, representing the eastern part of the study area.

To further demonstrate that the observed bimodal bathymetric distribution of the species was not due to the bathymetric distribution pattern of seagrasses, the same analysis was repeated excluding $\mathrm{PO}$ and $\mathrm{CN}$ habitat types. The same bimodal distribution was still observed (not shown here), indicating that this result is not related to the bathymetric distribution of seagrass beds.

The best model of the expected number of Caulerpa racemosa fronds (conditional on presence) was $g_{5}\left(w_{5}=\right.$ $57.5 \%)$, with $g_{7}$ also having substantial support $\left(\Delta_{7}=\right.$ $1.2, w_{7}=31.8 \%$ ) (Table 2 ). Thus, both models were used for inference. The other models had substantially less or essentially no support from the data. The expression of $g_{5}$ was $\log (\hat{n})=s($ time, 3.00$)+$ htype. The univariate smooth function of time and the estimated

Table 4. Aggregated results for each of the 20 line transects. The total number of sampled quadrats, the number of quadrats with Caulerpa racemosa, and the average and maximum measured densities at each transect are given

\begin{tabular}{|c|c|c|c|c|c|c|c|c|}
\hline \multirow[t]{2}{*}{ Site } & \multirow{2}{*}{$\begin{array}{l}\text { Latitude } \\
\qquad\left({ }^{\circ}\right)\end{array}$} & \multirow{2}{*}{$\begin{array}{l}\text { Longitude } \\
\qquad\left({ }^{\circ}\right)\end{array}$} & \multirow{2}{*}{$\begin{array}{c}\text { Sampling } \\
\text { date (2008) }\end{array}$} & \multirow{2}{*}{$\begin{array}{l}\text { Quadrats } \\
\text { sampled }\end{array}$} & \multirow{2}{*}{$\begin{array}{c}\text { Number of } \\
\text { non-zero counts }\end{array}$} & \multicolumn{3}{|c|}{ Density (fronds $400 \mathrm{~cm}^{-2}$ ) } \\
\hline & & & & & & $\begin{array}{l}\text { Overall } \\
\text { mean }\end{array}$ & $\begin{array}{c}\text { Mean of } \\
\text { non-zero counts }\end{array}$ & Maximum \\
\hline Thymari & 37.6922 & 23.9380 & $1 / 8$ & 40 & 14 & 2.3 & 6.6 & 26 \\
\hline Kalogerolimano & 37.8228 & 23.1462 & $23 / 8$ & 21 & 0 & 0.0 & - & 0 \\
\hline Sideronas & 37.8440 & 23.0391 & $23 / 8$ & 37 & 0 & 0.0 & - & 0 \\
\hline Koudounes & 37.7554 & 23.9020 & $26 / 8$ & 41 & 9 & 4.1 & 18.7 & 67 \\
\hline Legraina & 37.6694 & 23.9434 & $28 / 8$ & 21 & 9 & 14.4 & 33.6 & 63 \\
\hline South Perdika & 37.6877 & 23.4496 & $13 / 9$ & 41 & 0 & 0.0 & - & 0 \\
\hline West Marathonas & 37.7240 & 23.4500 & $13 / 9$ & 41 & 0 & 0.0 & - & 0 \\
\hline Peninta Braxia (east) & 37.7275 & 23.5407 & $14 / 9$ & 23 & 0 & 0.0 & - & 0 \\
\hline Bagies-Agioi (north) & 37.7726 & 23.5174 & $14 / 9$ & 41 & 2 & 0.2 & 4.0 & 7 \\
\hline Proto Limanaki & 37.8011 & 23.7855 & $17 / 9$ & 39 & 1 & 0.3 & 13.0 & 13 \\
\hline Lemonodasos (south) & 37.4601 & 23.5108 & $20 / 9$ & 41 & 1 & 0.1 & 4.0 & 4 \\
\hline Kalavria - Poros & 37.5157 & 23.5186 & $20 / 9$ & 33 & 0 & 0.0 & - & 0 \\
\hline Methana & 37.6399 & 23.3800 & $21 / 9$ & 41 & 1 & 0.0 & 1.0 & 1 \\
\hline Epidauros & 37.6229 & 23.1558 & $21 / 9$ & 33 & 0 & 0.0 & - & 0 \\
\hline Peristeria & 37.8773 & 23.4538 & $24 / 9$ & 41 & 0 & 0.0 & - & 0 \\
\hline Myloi Kokkini & 37.9184 & 23.0342 & $30 / 9$ & 41 & 0 & 0.0 & - & 0 \\
\hline Kineta & 37.9747 & 23.2389 & $17 / 10$ & 41 & 0 & 0.0 & - & 0 \\
\hline Ag. Kosmas & 37.8918 & 23.7165 & $1 / 11$ & 41 & 0 & 0.0 & - & 0 \\
\hline Galini & 37.9556 & 23.4386 & $2 / 11$ & 41 & 0 & 0.0 & - & 0 \\
\hline Thiafi & 37.6552 & 24.0100 & $15 / 11$ & 41 & 10 & 0.8 & 3.3 & 14 \\
\hline
\end{tabular}




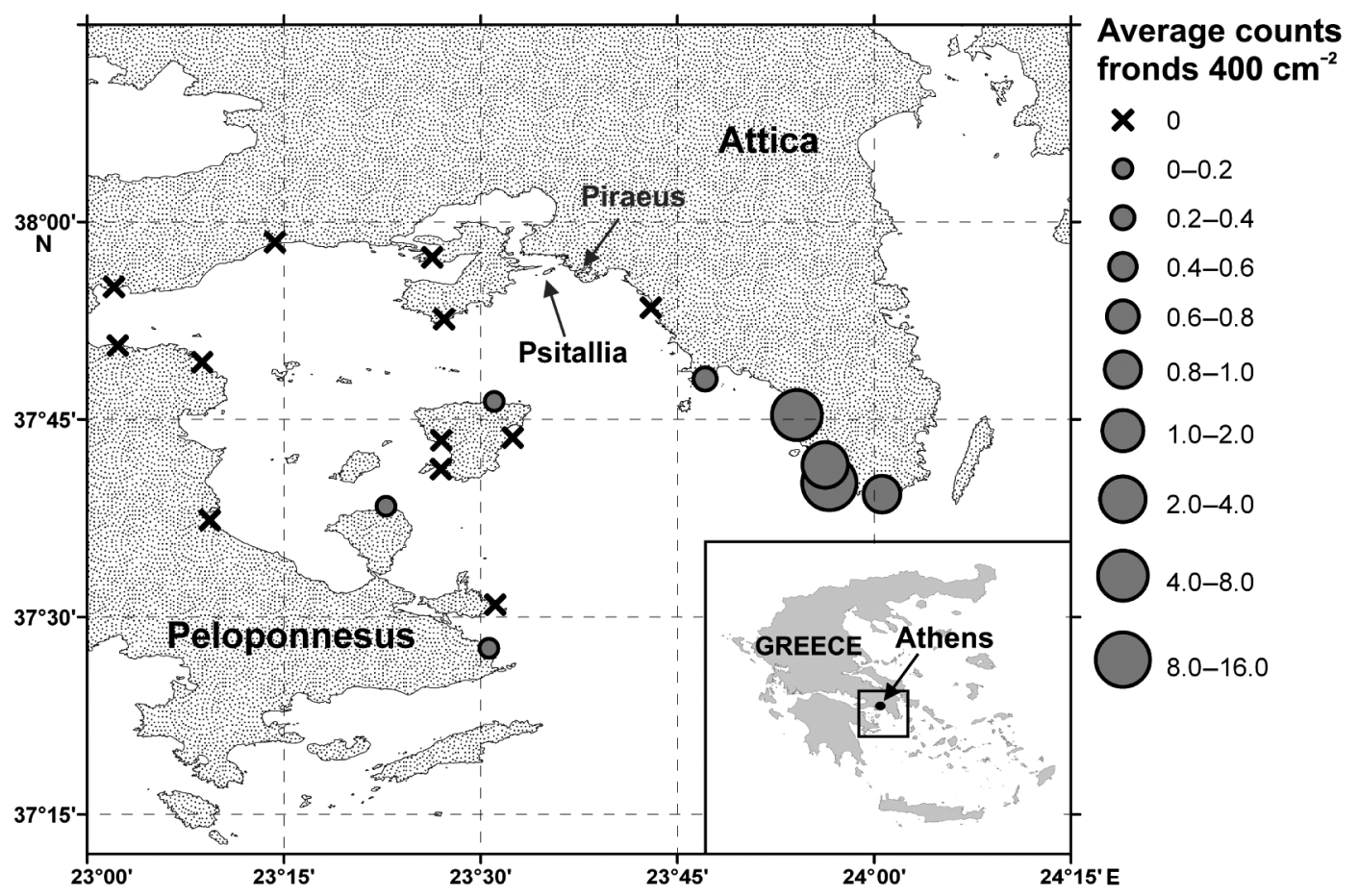

Fig. 1. Map of Saronikos Gulf showing the average counts of Caulerpa racemosa fronds in the $20 \times 20 \mathrm{~cm}$ plots of each transect
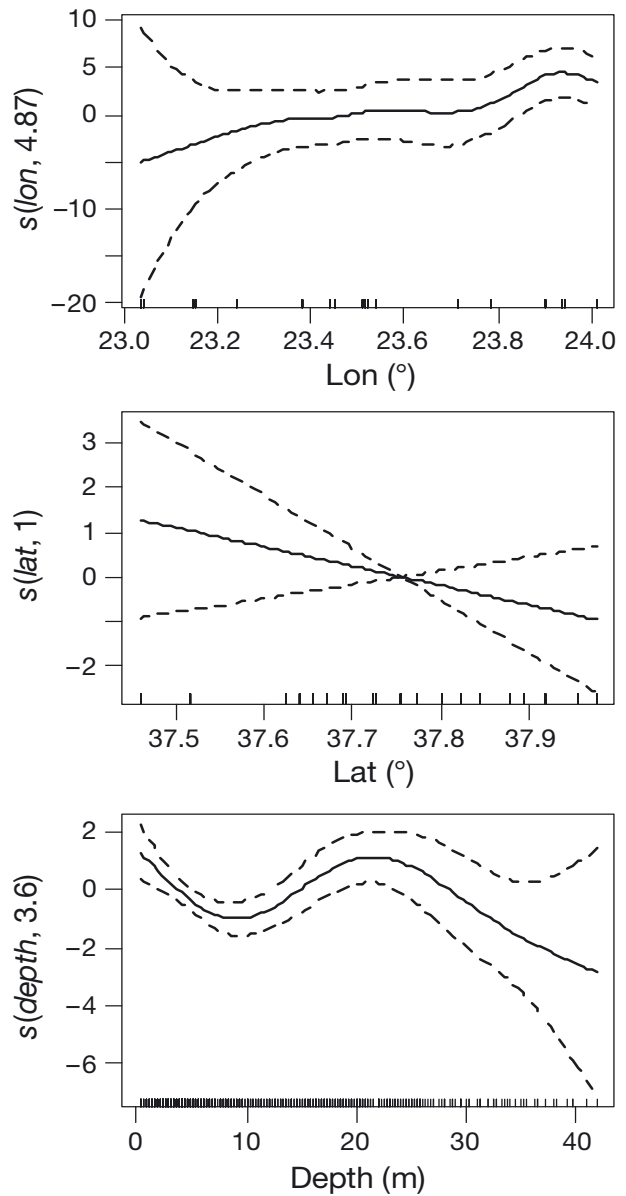
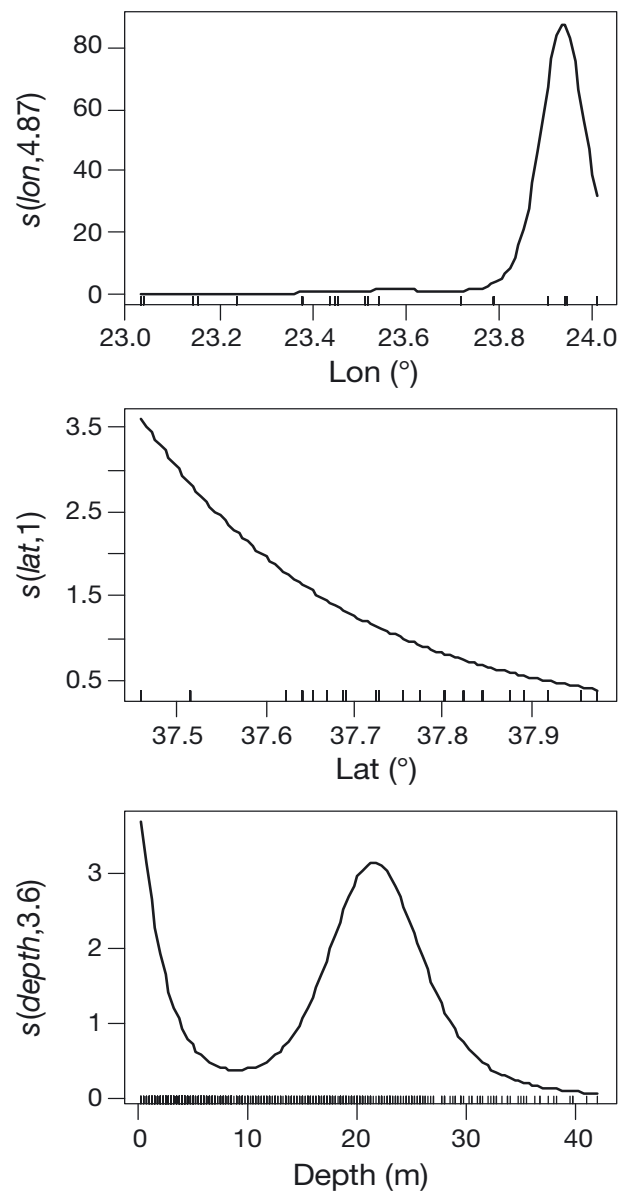

Fig. 2. Estimated smooth terms for the $h_{4}$ model of the probability of Caulerpa racemosa presence. In the left panels, the smooth terms are given in the linear predictor scale, i.e. in $\log (\mathrm{p} / 1-\mathrm{p})$, and the corresponding $95 \%$ CIs are indicated with dashed lines. In the right panels, the smooth terms are given in the 'odds of presence' scale, i.e. the smooth terms were exptransformed. The numbers after the commas in the $y$-axis titles are the estimated $\mathrm{df}$ of the smooth term. A 1-dimensional scatterplot (vertical bars) is given at the bottom of each graph to illustrate the distribution of available data 

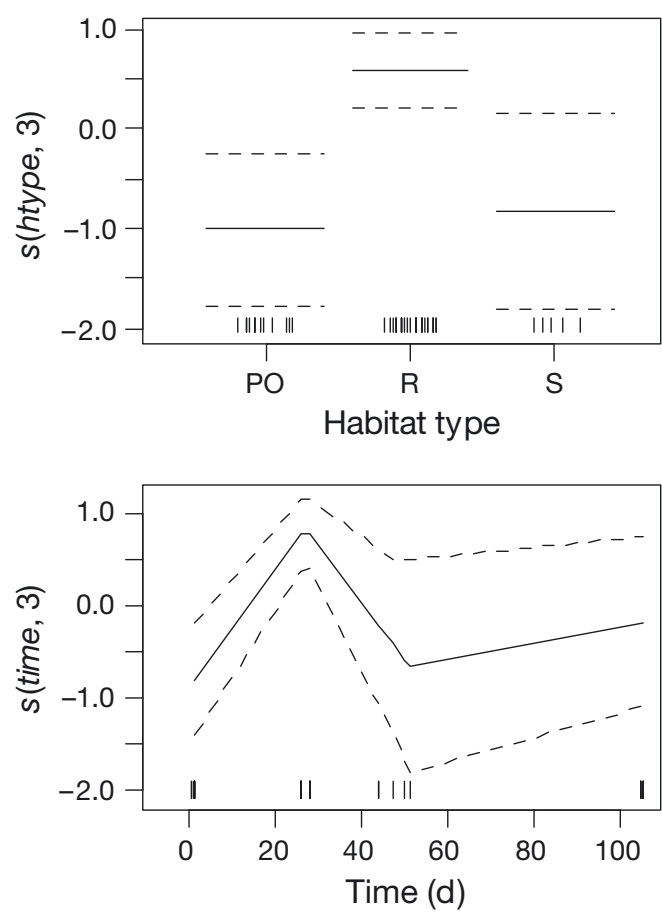

Fig. 3. Estimated smooth terms for the $g_{5}$ (left panels) and $g_{7}$ (right panels) models of Caulerpa racemosa abundance in $20 \times 20 \mathrm{~cm}$ plots. The smooth terms are given in the linear predictor scale, and the corresponding $95 \%$ CIs are indicated with dashed lines. The numbers after the commas in the $y$-axis titles are the estimated df of the smooth term. A 1-dimensional scatterplot (vertical bars) is given at the bottom of each graph to illustrate the distribution of available data. htype: habitat type (PO: Posidonia oceanica meadows; S: unvegetated sandy/muddy bottoms; R: rocky bottoms). Time was measured in days, with the value 1 corresponding to 1 August 2008

levels of htype are given in Fig. 3. The expression of $g_{7}$ was $\log (\hat{n})=s_{1}($ time, 2.93$)+s_{2}($ depth, 1.77 $)+$ htype. The univariate smooth functions and the levels of htype are also given in Fig. 3.

Frond density was markedly higher in rocky habitats than in Posidonia oceanica beds or on sandy/ muddy bottoms. The Caulerpa racemosa fronds within $P$. oceanica beds were mostly observed in the meadow limits or in sites of low seagrass density. In very shallow bottoms, although the probability of $C$. racemosa presence was high (model $h_{4}$; Fig. 2), the corresponding frond density was low compared to that at greater depths (Fig. 3). According to both $g_{5}$ and $g_{7}$, there was a peak in frond density at the end of August. However, this result should be viewed with caution due to the uneven temporal distribution of transects with C. racemosa and the low number of distinct values of time containing records of $C$. racemosa (8 values).
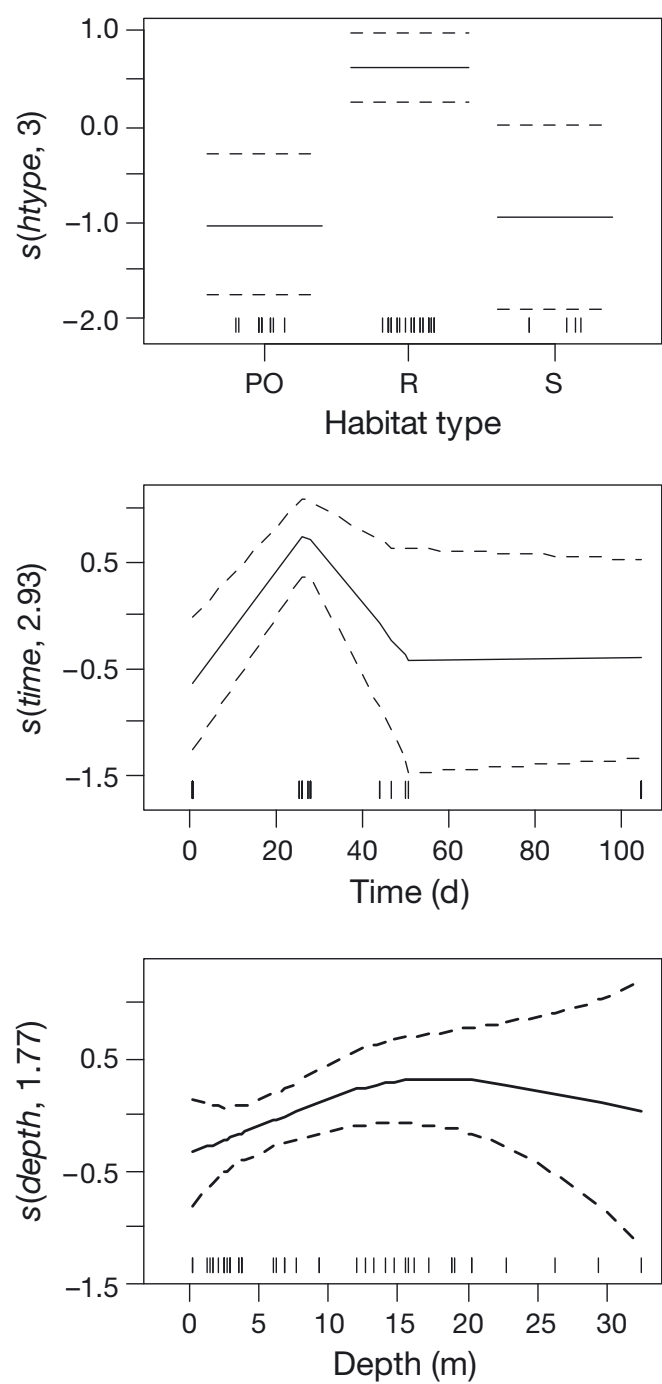

\section{DISCUSSION}

In the native range of Caulerpa racemosa in southwestern Australia, the bathymetric range of the species is restricted between the intertidal zone and a depth of $6 \mathrm{~m}$, and it is primarily found on reef flats and in intertidal pools (Klein \& Verlaque 2008). In the Mediterranean, C. racemosa features a much wider bathymetric range and has been observed to grow from the intertidal zone, sometimes partially emerged, down to a depth of $70 \mathrm{~m}$ (Raniello et al. 2006, Klein \& Verlaque 2008). At the lower limit of its bathymetric distribution, C. racemosa presence is sparse and occasional, while high abundances have been reported mostly in the range of 0 to $30 \mathrm{~m}$ (see Appendix A of Klein \& Verlaque 2008). A comparative investigation of the spatial distribution of C. racemosa over a wide bathymetric range has not been conducted prior to the present study. 
In the Saronikos Gulf, the probability of Caulerpa racemosa presence exhibited a bimodal bathymetric distribution with a first peak at very shallow depths $(<4 \mathrm{~m})$ and a second peak at depths between 15 and $30 \mathrm{~m}$. At greater depths, the probability of C. racemosa presence steadily decreased and was practically 0 at $40 \mathrm{~m}$. The lower limit of the bathymetric distribution is mainly affected by the efficiency of light exploitation through photochemical reactions, as light is a major factor that affects the photosynthetic performance and ultimately the growth performance of plants (Lobban et al. 1985). Raniello et al. (2006) reported on the photoacclimation capacity of C. racemosa, and indicated that the pigment siphonaxanthin is involved in acclimation to deep light regimes as well as photoprotection of shallow stands through regulated conversion into lutein.

The bimodal pattern of Caulerpa racemosa presence with depth (instead of a smooth decline from shallow to deeper areas) is difficult to interpret and is most likely related to the complexity of underlying effects. In conjunction with the nonlinear variation in light intensity with depth and the complex photochemical cycles, inherently nonlinear effects of abiotic parameters (temperature, hydrodynamics, salinity, dissolved oxygen, and nutrients) and ecological interactions with other species (e.g. predation or competition for space, light, and nutrients) may result in nonlinear patterns of spatial distribution. Moreover, moderate depths are much more stable environments in terms of both light availability and wave action, than are their deeper and shallower counterparts, respectively. These latter environments could thus be more prone to invasion by opportunists, such as C. racemosa, which is well known for its ability to exploit low light conditions (Raniello et al. 2006) and is commonly found in wave-exposed shores (Klein \& Verlaque 2008).

Bimodal bathymetric distribution has been observed for laminarian algae in subtidal regions of northern New Zealand, with peaks of abundance at the 3 to $6 \mathrm{~m}$ and 10 to $17 \mathrm{~m}$ bathymetric zones (Choat \& Schiel 1982). This bimodal feature was consistent over a wide geographic range of the northern coastal sites and for semi-exposed offshore islands in New Zealand. This pattern was attributed to the bathymetric distribution of invertebrate herbivores (echinoids and gastropods) that were primarily abundant at intermediate depths (6 to $10 \mathrm{~m}$ ). Prediction models of the expansion of the congeneric species Caulerpa taxifolia suggested a single depth stratum (between 5 to $10 \mathrm{~m}$ ) of high risk of invasion (Hill et al. 1998), indicating different patterns of bathymetric distribution between the 2 species.

The abundance (conditional on presence) of Caulerpa racemosa in Posidonia oceanica beds was lower than that on rocky bottoms, and appeared to be influ- enced by seagrass density. In a multifactorial experiment, Ceccherelli et al. (2000) tested the effect of $P$. oceanica canopy structure on frond size, stolon growth, and percent cover of C. racemosa. Their results indicated that both the vertical and horizontal algal growth was negatively influenced by seagrass density, and that dense and healthy $P$. oceanica meadows represent a barrier to the colonization of $C$. racemosa. Other studies (see Klein \& Verlaque 2008 for a review) have also reported that C. racemosa is seemingly unable to penetrate dense $P$. oceanica meadows but is often found on the rhizomes at the margins of the meadow or in sparse beds. Although a significant increase in the abundance of $C$. racemosa on and around dead 'mats' of $P$. oceanica has been frequently reported in the literature (Klein \& Verlaque 2008 and references therein), the absence of this type of substrate did not permit the substantiation of such a relationship in the surveyed region. Large patches of dead mats seem to be more or less absent from the Saronikos Gulf (authors' pers. obs., P. Panayotidis pers. comm.). Indeed, the only documentation of such a conspicuous ecomorphosis dates back to 1988 and is geographically restricted to the greater area of Piraeus port (Panayotidis 1988).

Dense beds of Cymodocea nodosa might also represent an obstruction to Caulerpa racemosa invasion. In this study, zero C. racemosa abundance was observed in all quadrats within C. nodosa beds ( $\mathrm{n}=37$ ). However, no conclusions can be reached on the vulnerability of $C$. nodosa meadows to $C$. racemosa invasion since all $C$. nodosa beds (found in 4 line transects) were observed in the western Saronikos Gulf where C. racemosa was generally absent.

Caulerpa racemosa abundance on unvegetated sandy/muddy bottoms was lower than that on rocky bottoms and similar to that in Posidonia oceanica beds. Under certain conditions, C. racemosa may form compact dense mats on soft bottoms (Argyrou et al. 1999, Klein \& Verlaque 2008). Although such mats have been observed in the Aegean Sea (e.g. in the outer Souda Bay in Crete Island; Katsanevakis \& ThessalouLegaki 2009), no dense mats were observed in softsubstrate areas in this study in the Saronikos Gulf.

Since 1996 when Caulerpa racemosa was first observed in the southeastern Saronikos Gulf (Panayotidis \& Montesanto 2001), the species has progressively colonized numerous other sites, exhibiting an anticlockwise propagation along the coastline (Fig. 4; Panayotidis et al. 2006, K. Tsiamis pers. comm.). The species is still absent from the westernmost parts of the gulf and is still very infrequent from the sites of recent detection (which is the reason why we did not record it during this study in some sites of documented presence). In this study, the highest densities were found in 


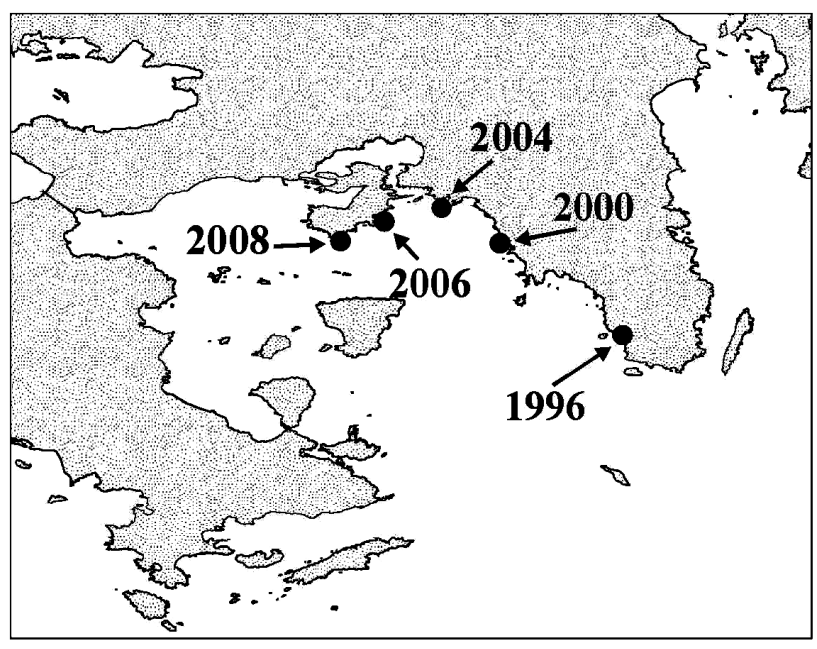

Fig. 4. Historical records of Caulerpa racemosa in the Saronikos Gulf from the date of first occurrence (1996) to 2008 (Panayotidis et al. 2006, K. Tsiamis pers. comm.). These sites have been monitored in the framework of the ecological monitoring of the Saronikos Gulf conducted by the Hellenic Centre for Marine Research

the reported area of first colonization (southeastern Saronikos). When a site is invaded by C. racemosa, the alga appears to continue its range extension and increase its cover and frond density. In most of the invaded sites in the Mediterranean, no decline in colonized surfaces has been reported (Klein \& Verlaque 2008). The length of the time period from the initial colonization appears to be an important factor that determines the frond density of the species. Therefore, high frond densities, such as those currently observed in the southeastern Saronikos Gulf, are expected to occur in most of the eastern coast during the following decade.

In practice, the usual approach followed when investigating the relations between ecological variables is to assume a specific parametric form (often linear) and apply multiple regression techniques. A more appropriate approach is to fit a flexible nonparametric model that could attain a great variety of patterns and does not assume functional relationships between the predictor and response variables, rather than to adopt a specific parametric form. Ecological phenomena, such as the spatial distribution of a species, are usually complex and are being driven apart from the main dominant effects by many other smaller effects that are difficult to detect. The variable environment, composite interspecific relationships (e.g. competition and predation), individual heterogeneity, and rare events may have important effects and add further complexity. In the present study, GAMs were used to offer the required flexibility and overcome the limiting concept of a strict parametric shape in ecological relationships. The use of such flexible models is recommended in studies relating abundance of marine fauna or flora to environmental and spatial predictors. In addition, the information theory approach for inference strengthens the validity of the results and provides increased robustness compared to classical approaches for modelling and model selection (Burnham \& Anderson 2002, Katsanevakis \& Maravelias 2008).

Acknowledgements. We thank P. Panayotidis and K. Tsiamis for reviewing an initial version of the manuscript and making useful comments and suggestions. The useful comments of 4 anonymous reviewers helped us to improve the quality of the manuscript.

\section{LITERATURE CITED}

Akaike $H$ (1973) Information theory as an extension of the maximum likelihood principle. In: Petrov BN, Csaki F (eds) Proc 2nd Int Symp on Information Theory. Akademiai Kiado, Budapest, p 267-281

Akaike H (1981) Likelihood of a model and information criteria. J Econom 16:3-14

Akaike H (1983) Information measures and model selection. Bull Int Stat Inst 44:277-290

Argyrou M, Demetropoulos A, Hadjichristophorou M (1999) Expansion of the macroalga Caulerpa racemosa and changes in softbottom macrofaunal assemblages in Moni Bay, Cyprus. Oceanol Acta 22:517-528

Baldacconi R, Corriero G (2009) Effects of the spread of the alga Caulerpa racemosa var. cylindracea on the sponge assemblage from coralligenous concretions of the Apulian coast (Ionian Sea, Italy). PSZNI: Mar Ecol 30:337-345

Barry SC, Welsh AH (2002) Generalized additive modelling and zero inflated count data. Ecol Modell 157:179-188

> Buckland ST, Burnham KP, Augustin NH (1997) Model selection: an integral part of inference. Biometrics 53:603-618

Burnham KP, Anderson D (2002) Model selection and multimodel inference. Springer, Berlin

> Ceccherelli G, Piazzi L (2001) Dispersal of Caulerpa racemosa fragments in the Mediterranean: lack of detachment time effect on establishment. Bot Mar 44:209-213

> Ceccherelli G, Piazzi L, Cinelli F (2000) Response of the nonindigenous Caulerpa racemosa (Forsskål) J. Agardh to the native seagrass Posidonia oceanica (L.) Delile: effect of density of shoots and orientation of edges of meadows. J Exp Mar Biol Ecol 243:227-240

Choat JH, Schiel DR (1982) Patterns of distribution and abundance of large brown algae and invertebrate herbivores in subtidal regions of Northern New Zealand. J Exp Mar Biol Ecol 60:129-162

Craven P, Wahba G (1979) Smoothing noisy data with spline functions. Estimating the correct degree of smoothing by the method of generalized cross-validation. Numer Math 31:377-403

Daskalov GM, Boyer DC, Roux JP (2003) Relating sardine Sardinops sagax abundance to environmental indices in northern Benguela. Prog Oceanogr 59:257-274

Hastie TJ, Tibshirani RJ (1990) Generalized additive models (monographs on statistics and applied probability). Chapman \& Hall/CRC, London

Herr H, Scheidat M, Lehnert K, Siebert U (2009) Seals at sea: 
modelling seal distribution in the German bight based on aerial survey data. Mar Biol 156:811-820

Hill D, Coquillard P, de Vaugelas J, Meinesz A (1998) An algorithmic model for invasive species: application to Caulerpa taxifolia (Vahl) C. Agardh development in the north-western Mediterranean Sea. Ecol Modell 109: 251-265

Katsanevakis S (2007) Density surface modelling with line transect sampling as a tool for abundance estimation of marine benthic species: the Pinna nobilis example in a marine lake. Mar Biol 152:77-85

Katsanevakis S, Maravelias CD (2008) Modelling fish growth: multi-model inference as a better alternative to a priori using von Bertalanffy equation. Fish Fish 9:178-187

Katsanevakis S, Thessalou-Legaki M (2009) Spatial distribution and abundance of the endangered fan mussel Pinna nobilis in Souda Bay (Crete Island, Greece). Aquat Biol 8:45-54

Klein J, Verlaque M (2008) The Caulerpa racemosa invasion: a critical review. Mar Pollut Bull 56:205-225

Kontoyiannis H, Krestenitis I, Petihakis G, Tsirtsis G (2005) Coastal areas: circulation and hydrological features. In: Papathanassiou E, Zenetos A (eds) State of the Hellenic marine environment. Hellenic Centre for Marine Research, Athens, p 95-103

Kružić P, Zuljević A, Nikolić V (2008) The highly invasive alga Caulerpa racemosa var. cylindracea poses a new threat to the banks of the coral Cladocora caespitosa in the Adriatic Sea. Coral Reefs 27:441

Laidre KL, Heide-Jørgensen MP, Heagerty P, Cossio A, Bergström B, Simon M (2010) Spatial associations between large baleen whales and their prey in West Greenland. Mar Ecol Prog Ser 402:269-284

Lobban CS, Harrison PJ, Duncan MJ (1985) The physiological ecology of seaweeds. Cambridge University Press, Cambridge

Macic V, Kascelan S (2007) Caulerpa racemosa on the Montenegrian Coast. Rapp Comm Int Mer Mediterr 38:533

> Maravelias CD, Tsitsika EV, Papaconstantinou C (2007) Evidence of Morocco dentex (Dentex maroccanus) distribution in the NE Mediterranean and relationships with environmental factors determined by Generalized Additive Modelling. Fish Oceanogr 16:294-302

Martin TG, Wintle BA, Rhodes JR, Kuhnert PM and others (2005) Zero tolerance ecology: improving ecological inference by modelling the source of zero observations. Ecol Lett 8:1235-1246

Meinesz A, Hesse B (1991) Introduction et invasion de l'algue tropicale Caulerpa taxifolia en Mediterranée Nord-occidentale. Oceanol Acta 14:415-426

Murase H, Nagashima H, Yonezaki S, Matsukura R, Kitakado $T$ (2009) Application of a generalized additive model (GAM) to reveal relationships between environmental factors and distributions of pelagic fish and krill: a case study in Sendai Bay, Japan. ICES J Mar Sci 66:1417-1424

Nizamuddin M (1991) The green marine algae of Libya. Elga Publisher, Bern

Orfanidis S, Panayotidis P, Stamatis N (2001) Ecological evaluation of transitional and coastal waters: a marine benthic macrophytes-based model. Mediterr Mar Sci 2:45-65

Panayotidis P (1988) Etude de l'impact de la pollution sur les herbiers de Posidonia oceanica (Linnaeus) Delile, dans le golfe de Saronikos (Mer Egee. Grece). MAP Tech Rep Ser 22:85-104

Panayotidis P (2006) On the enigmatic origin of the Mediterranean invasive Caulerpa racemosa (Caulerpales, Chlorophyta). Mediterr Mar Sci 7:119-121
Panayotidis P, Montesanto B (1994) Caulerpa racemosa (Chlorophyta) on the Greek coasts. Cryptogam, Algol 15:159-161

Panayotidis P, Montesanto B (1998) Recent expansion of Caulerpa racemosa (Chlorophyta) in the Mediterranean. In: Boudouresque CF, Gravez V, Meinesz A, Palluy F (eds) 3rd Int Workshop on Caulerpa taxifolia. GIS Posidonie, Marseille, p 239-241

Panayotidis P, Montesanto B (2001) Occurrence and phytosociology of Caulerpa racemosa in Saronikos Gulf (Aegean Sea, Greece). In: Gravez V, Ruitton S, Boudouresque CF, Le Direac'h L, Meinesz A, Scabbia G, Verlaque M (eds) 4th Int Workshop on Caulerpa taxifolia. GIS Posidonie, Marseilles, p 334-337

Panayotidis P, Zuuljević A (2001) Sexual reproduction of the invasive green alga Caulerpa racemosa var. occidentalis in the Mediterranean Sea. Oceanol Acta 24:199-203

Panayotidis P,Žuljević A, Montesanto B (2006) Sexual reproduction of the invasive green alga Caulerpa racemosa in the Mediterranean Sea, as a key to understand its rapid expansion and its origin. 8th Hellenic Symp on Oceanography and Fisheries. Hellenic Centre for Marine Research, Athens, p 419-422

Piazzi L, Balestri E, Magri M, Cinelli F (1997) Expansion de l'algue tropicale Caulerpa racemosa (Forsskal) J. Agardh (Bryopsidophyceae, Chlorophyta) le long de la côte Toscane (Italie). Cryptogam, Algol 18:343-350

Piazzi L, Meinesz A, Verlaque M, Akcali B and others (2005) Invasion of Caulerpa racemosa var. cylindracea (Caulerpales, Chlorophyta) in the Mediterranean sea: an assessment of the spread. Cryptogam, Algol 26:189-202

Pimentel D, Zuniga R, Morrison D (2005) Update on the environmental and economic costs associated with alieninvasive species in the United States. Ecol Econ 52: 273-288 doi:10.1016/j.ecolecon.2004.10.002

R Development Core Team (2007) R: a language and environment for statistical computing. R Foundation for Statistical Computing, Vienna, Austria, available at www.R-project.org

Raniello R, Lorenti M, Brunet C, Buia MC (2006) Photoacclimation of the invasive alga Caulerpa racemosa var. cylindracea to depth and daylight patterns and a putative new role for siphonaxanthin. PSZNI: Mar Ecol 27:20-30

Renoncourt L, Meinesz A (2002) Formation of propagules on an invasive strain of Caulerpa racemosa (Chlorophyta) in the Mediterranean Sea. Phycologia 41:533-535

Simboura N, Panayotidis P, Papathanassiou E (2005) A synthesis of the biological quality elements for the implementation of the European Water Framework Directive in the Mediterranean Ecoregion: the case of Saronikos Gulf. Ecol Indic 5:253-266

Stasinopoulos DM, Rigby RA (2007) Generalized additive models for location, scale, and shape (GAMLSS) in R. J Stat Soft 23:1-46

Streftaris N, Zenetos A (2006) Alien marine species in the Mediterranean-the 100 'worst invasives' and their impact. Mediterr Mar Sci 7:87-118

Tsiamis K, Panayotidis P, Zenetos A (2008) Alien marine macrophytes in Greece: a review. Bot Mar 51:237-246

Tsiamis K, Montesanto B, Panayotidis P, Katsaros C, Verlaque $M$ (2010) Updated records and range expansion of alien marine macrophytes in Greece (2009). Mediterr Mar Sci 11:61-79

> Verlaque M, Boudouresque CF, Meinesz A, Gravez V (2000) The Caulerpa racemosa complex (Caulerpales, Ulvophyceae) in the Mediterranean Sea. Bot Mar 43:49-68

Verlaque M, Durand C, Huisman JM, Boudouresque CF, Le 
Parco Y (2003) On the identity and origin of the Mediterranean invasive Caulerpa racemosa (Caulerpales, Chlorophyta). Eur J Phycol 38:325-339

- Verlaque M, Afonso-Carrillo J, Candelaria Gil-Rodríguez M, Durand C, Boudouresque CF, Le Parco Y (2004) Blitzkrieg in a marine invasion: Caulerpa racemosa var. cylindracea (Bryopsidales, Chlorophyta) reaches the Canary Islands (North-East Atlantic). Biol Invasions 6:269-281

Verlaque M, Ruitton S, Mineur F, Boudouresque CF (in press) CIESM atlas of exotic species in the Mediterranean, Vol 4. Macrophytes. CIESM Publishers, Monaco

Welsh AH, Cunningham RB, Donnelly CF, Lindenmayer DB (1996) Modelling the abundance of rare species: statistical models for counts with extra zeros. Ecol Modell 88: 297-308

Wood SN (2000) Modelling and smoothing parameter estima-

Editorial responsibility: Hans Heinrich Janssen, Oldendorf/Luhe, Germany tion with multiple quadratic penalties. J R Stat Soc Ser B Stat Methodol 62:413-428

Wood S (2006) Generalized additive models: an introduction with R (texts in statistical science). Chapman \& Hall/CRC, Boca Raton, FL

Zenetos A, Meriç M, Verlaque P, Galli P and others (2008) Additions to the annotated list of marine alien biota in the Mediterranean with special emphasis on Foraminifera and parasites. Mediterr Mar Sci 9:119-165

Zenetos A (2010) Trend in aliens species in the Mediterranean. An answer to Galil, 2009 'Taking stock: inventory of alien species in the Mediterranean Sea'. Biol Invas

Zeri C, Kontoyiannis H, Giannakourou A (2009) Distribution, fluxes and bacterial consumption of total organic carbon in a populated Mediterranean Gulf. Cont Shelf Res 29: 886-895

Submitted: February 8, 2010; Accepted: June 2, 2010

Proofs received from author(s): July 7, 2010 